\title{
LOS NUEVOS DERECHOS SOCIALES: EL DERECHO AL CUIDADO COMO FUNDAMENTO DEL PACTO CONSTITUCIONAL
}

ANA MARRADES 
SUMARIO

1. EVOLUCIÓN Y CONCEPTO DE LOS DERECHOS SOCIALES: EL NUEVO CONTEXTO HISTÓRICO Y SOCIAL. 1.1 La evolución de los derechos sociales. 1.2 El carácter fundamental de los derechos sociales. 1.3 Los derechos sociales ante el cambio constitucional. 2. EL CUIDADO: UNA «FUNCIÓN DE LAS MUJERES». 2.1 La ética del cuidado. 2.2 Los problemas del cuidado y las personas dependientes. 3. COMO CONCLUSIÓN: UN DERECHO AL CUIDADO. 


\title{
LOS NUEVOS DERECHOS SOCIALES: EL DERECHO AL CUIDADO COMO FUNDAMENTO DEL PACTO CONSTITUCIONAL
}

\author{
ANA MARRADES ${ }^{1}$ \\ Universidad de Valencia
}

\section{EVOLUCIÓN Y CONCEPTO DE LOS DERECHOS SOCIALES: EL NUEVO CONTEXTO HISTÓRICO Y SOCIAL}

El Pacto Internacional de Derechos Económicos, Sociales y Culturales reconoce que «con arreglo a la Declaración Universal de Derechos Humanos, no puede realizarse el ideal del ser humano libre a menos que se creen las condiciones que permitan a cada persona gozar de sus derechos económicos, sociales y culturales, tanto como sus derechos civiles y políticos». Éste fue el punto de partida para resaltar la necesidad de reconocer unos derechos que comenzaban a ser considerados esenciales para una vida digna. Las constituciones democráticas fueron incorporándolos en sus textos aunque con un valor diferente a los llamados derechos fundamentales, atribuyendo sólo a éstos la categoría de universales; sin embargo los derechos sociales son también universales por su condición de derechos humanos.

Nuestra Constitución propugna como valores superiores la libertad, la justicia y la igualdad en el marco de un Estado social y democrático de Derecho,

\footnotetext{
1 Ana Marrades Puig. Profesora Contratada Doctora. Departamento de Derecho Constitucional. Ciencia Política y de la Administración. Facultad de Derecho. Universidad de Valencia. Avenida de los Naranjos, s/n. 46022 Valencia Email: ana.i.marrades@uv.es
} 
consistente, en palabras de Antonio Torres del $\mathrm{Moral}^{2}$, en un sistema de solidaridad nacional gestionado por los poderes públicos con la participación ciudadana y el respeto al Derecho y a los derechos. Dentro de ellos hay que considerar de manera esencial los sociales porque son imprescindibles para hacer efectiva la solidaridad y la digna calidad de vida que también el Preámbulo de nuestra Constitución proclama. Frente a quienes sostienen que esta declaración carece de valor normativo, Torres del Moral mantiene que contiene un principio estructural de primer orden que se desarrolla a lo largo de todo el articulado y que, además, impregna todo el texto constitucional y el resto del Ordenamiento jurídico, que hay que interpretar a la luz de dicha declaración y de los valores que propugna, por tanto es una norma constitutiva del régimen que nuestra constitución instaura. Por eso es importante revisar el concepto y la categorización de los derechos de solidaridad.

La Constitución española establece tres grupos de derechos a los que atribuye, según su importancia, distintas garantías: los derechos fundamentales, los derechos (no enunciados como fundamentales) y los principios rectores de la política social y económica entre los cuales se enuncian algunos derechos de los denominados «sociales», por ejemplo el derecho a la protección de la salud, a una vivienda digna, a la protección de la familia, de los hijos, de las madres, o el derecho a disfrutar de un medio ambiente adecuado para el desarrollo de la persona.

Muchos de estos derechos sociales por su importancia y por la necesidad de ser dotados de las máximas garantías deberían tener la consideración de fundamentales. También muchos de los de la sección 2.a , del Capítulo II. Y por otro lado, creo que muchos de los derechos de la sección $1 .{ }^{a}$ son además de fundamentales, derechos sociales.

Esta reflexión nos lleva a considerar que ya no resulta adecuada la categorización de los derechos que hace la Constitución por lo que debería realizarse una reforma constitucional que afectara a los derechos en dos sentidos: reubicar los derechos concediendo a los derechos sociales la categoría de fundamentales, amparándoles por tanto con las mejores garantías y por otro lado, plantearse la conveniencia de introducir nuevos derechos sociales-fundamentales como los derechos del cuidado.

2 Torres Del Moral, A. (2006) «Democracia militante», en Pérez Royo, J.; Urías Martínez, J. y Carrasco Durán, M., Derecho Constitucional para el siglo XXI, Navarra, Aranzadi, p. 222. 
Creo como dice Luís Jimena ${ }^{3}$, en el carácter indivisible y fundamental de los derechos humanos y por tanto de los derechos sociales; y también en que, como explica Ruiz Miguel, no debería haber diferencias sustanciales entre derechos fundamentales y derechos sociales en cuanto a su fundamentación, titularidad y mecanismos de protección y de garantía ya que «según una postura o función progresista, los derechos liberales son condición previa pero no suficiente de libertad y de igualdad, que sólo serían reales y efectivas con la completa extensión de los derechos sociales». Pero esto no es así, a pesar de que, como expone el mencionado autor ${ }^{4}$ "algunos derechos civiles y políticos comparten más rasgos, y bastante relevantes, con algunos derechos sociales que con otros derechos civiles y políticos» ya que las constituciones establecen, especialmente la española, una ubicación específica para cada grupo de derechos y dotan a cada uno de ellos de un diferente mecanismo de protección y garantía según la consideración que para la constitución tiene cada grupo, por lo que convendría su revisión para adaptarse al nuevo contexto político-social actual.

\subsection{La evolución de los derechos sociales}

La distinción entre los grupos de derechos tiene su origen en las distintas generaciones de derechos 5 . Las primeras manifestaciones de derechos sociales surgen el siglo $\mathrm{XX}$, tras la crisis del estado liberal, incapaz de hacer frente a las nuevas demandas sociales. A pesar de eso, la estrategia de gobierno se fundamenta sobre la defensa de la propiedad privada, pero a la vez, se separa del liberalismo doctrinario y atribuye al Estado la tarea de mediar el conflicto, intervenir

3 Jimena Quesada, L. (2012) «La tutela de los derechos sociales: El espacio de la Unión y del Consejo de Europa», en Cascajo Castro, J. L, Terol Becerra, M., Domínguez Vila, A. y Navarro Marchante, V, Derechos Sociales y principios rectores, Actas del IX Congreso de la Asociación de Constitucionalistas de España, Valencia, Tirant lo Blanch, p.135.

${ }^{4}$ Ruiz Miguel, A. (2013) «Derechos y libertades y derechos sociales», Los derechos sociales en el estado constitucional, Tirant lo Blanch, Valencia, pp.175-177.

5 Atendiendo a la clasificación de las generaciones de derechos, los derechos sociales se situarían en la segunda generación de derechos después de la primera generación de los derechos individuales o derechos de libertad según la mayoría de la doctrina; y podrían abarcar o incluir algunos de la tercera generación (derechos nuevos democráticos); para otro sector serían derechos de la tercera generación, porque se consideran los derechos políticos, o colectivos, como de segunda generación distinguiéndose de los derechos de libertad o individuales, ubicando así los derechos sociales en la tercera generación y creando tras ellos una cuarta generación de derechos nuevos. SÁnChez Ferriz, R. (1995) Estudio sobre las libertades, Valencia, Tirant lo Blanch.

En relación con la teoría general de los derechos sociales también puede verse AÑón RoIG, M. J. y García AÑón, J. (2002) Lecciones de derechos sociales, Valencia, Tirant lo Blanch. 
apoyando a las personas más débiles, a las clases menos privilegiadas, que en definitiva, podrían poner en peligro la estabilidad del sistema ${ }^{6}$. Por eso y para asegurar unos mínimos vitales, unas oportunidades básicas mínimas surgen los derechos sociales en el marco del estado social a lo largo del siglo xx. El primer ingreso de estos derechos en un orden jurídico positivo tuvo lugar en Alemania, después de la primera guerra mundial con la Constitución de Weimar, en $1919^{7}$. Aunque esas primeras manifestaciones no dejaban de ser una declaración de intenciones para dar cabida a los derechos civiles, políticos, y sociales; para conciliar los derechos de la esfera de la autonomía individual con la responsabilidad social del Estado. Sin embargo sirvieron de mucho, especialmente para poner el foco en los derechos sociales y comenzar a hablar de ellos.

La que podría ser la segunda etapa de los derechos sociales se inicia en 1945, tras el fin de la segunda guerra mundial. El estado de derecho se ha transformado en un estado de «derechos», como explica José Asensi, un sistema que no sólo funciona como garantía contra la arbitrariedad del poder sino como promotor de determinados fines u objetivos sociales ${ }^{8}$. Así, los estados democráticos de derecho resaltan el reconocimiento de los derechos sociales como un componente esencial del nuevo orden constitucional, para aminorar las desigualdades y luchar contra las injusticias que, en el mundo contemporáneo — citando a Manuel Atienzatienen como «rasgo central, el abismo cada vez mayor entre los ricos y los pobres, entre los poderosos y los sometidos, un abismo que separa no sólo a unas sociedades de otras, sino a unos individuos de otros que forman parte de la misma sociedad» ${ }^{9}$. La tarea principal de los derechos sociales sería pues, hacer una sociedad más justa. Sin embargo hay que tener en cuenta que la mayoría de constituciones de la segunda posguerra (la italiana o la francesa) son constituciones-proyecto ${ }^{10}$ porque no describen un orden existente sino que son más bien, líneas de construcción de un nuevo edificio que debe ser actualizado a través de la acción del legislador, tomando en serio los derechos sociales prometidos por el texto constitucional pero todavía no realizados.

${ }^{6}$ Costa, P. (2013) «Derechos sociales y democracia constitucional: un itinerario histórico», Los derechos sociales en el estado constitucional, Valencia, Tirant lo Blanch, pp. 34 y 35.

7 Si bien podríamos hablar de la Constitución mejicana como la primera en incorporar derechos sociales. Cossío Díaz, J. R. (2015) «Políticas públicas, exigibilidad y justiciabilidad de los derechos sociales», en Derechos sociales. Políticas públicas, exigibilidad y justiciabilidad (Dir. Zúñiga, A. V. y Córdoba, E.), Pamplona, Aranzadi.

8 Asensi Sabater, J. (1998) La época constitucional, Valencia, Tirant lo blanch, p. 190 y ss.

9 Atienza Rodríguez, M. (2012), El sentido del Derecho, Barcelona, Ariel, p. 324.

${ }^{10}$ Costa, ob. cit, p. 41. 
Las constituciones de los setenta, por ejemplo la Constitución española, aparecen en un contexto social nuevo, incluso de un nuevo modelo de estado social que parecía estar entrando en crisis, para el que las ciencias sociales buscan un nuevo contexto donde pueda sobrevivir. Ésta podría ser la llamada «tercera vía» que propone vincular la realización de los derechos sociales con las libertades individuales y la responsabilidad del individuo ${ }^{11}$. En ese marco debería analizarse el concepto, la naturaleza y la eficacia de los derechos sociales actualmente, algunos de los cuales son también auténticos derechos fundamentales porque forman parte del ámbito de la esfera de la autonomía individual por un lado y por otro, porque proyectan las obligaciones y la responsabilidad del Estado de proporcionar las condiciones para una vida digna.

La particular situación política por la que atraviesa España en el momento de redactar este trabajo hace prever posibles cambios constitucionales en un nuevo contexto social. Se habla de una segunda transición, de una reforma constitucional, de un cambio seguro ante un panorama incierto, incluso de un proceso constituyente $^{12}$. Es preciso por tanto reformular el pacto social, un nuevo pacto que tome en cuenta nuevas necesidades y expectativas, para ello resulta imprescindible replantearse los derechos en el nuevo texto constitucional. Qué nuevos derechos habría que incluir, cuáles habría que modificar y cómo deberían ser clasificados y sobre todo reflexionar sobre el carácter fundamental de los derechos sociales.

\subsection{El carácter fundamental de los derechos sociales}

Los derechos sociales son derechos fundamentales sólo si el constituyente los configura y los organiza con las características y garantías propias de la funda-

${ }_{11}$ Por ejemplo, la recomendada por Giddens, A., en La tercera vía: la renovación de la socialdemocracia (1998). También ver La tercera vía y sus críticos (2000).

12 Aunque de momento está bastante claro que no es esa la voluntad de los partidos mayoritarios. Véase por ejemplo el «Acuerdo para un Gobierno reformista y de progreso» entre PSOE y Ciudadanos (firmado el 24/2/2016) donde ambos partidos afirmaban que: «Orgullosos de la Constitución, no pretendemos abrir un proceso constituyente sino mantener los principios e instituciones esenciales de la misma, fortalecer los derechos reconocidos a los ciudadanos y adecuar su texto a las transformaciones experimentadas por nuestra sociedad». La doctrina constitucional mayoritaria se decanta por una reforma — parcial o total — algunos incluso por un proceso constituyente. Pérez Royo hace un análisis sobre el problema de legitimidad para el cambio constitucional si no se sustituyen los fundamentos de nuestra Constitución que la hacen estéril porque cierran el camino de la reforma. PÉREz Royo, J. (2015) La reforma constitucional inviable, Madrid, Catarata, p. 45. 
mentalidad de la norma constitucional. Estas palabras de Bastida ${ }^{13}$ parecen mostrar la explicación obvia y formalista a la que suele acudir la doctrina cuando pretende explicar la naturaleza de los derechos sociales. Partiendo de los requisitos de «fundamentalidad» un derecho llegará a serlo (a ser fundamental) en tanto que cumpla esos requisitos: características y garantías. En cuanto a las características básicamente habría que referirse a la «disponibilidad del derecho por su titular y la indisponibilidad de su existencia por el legislador» ${ }^{14}$; y respecto a sus garantías habría que referirse a la posibilidad de ser protegido por el recurso de amparo.

La justiciabilidad de estos derechos es un factor de importancia si consideramos que aunque un Estado cumpla habitualmente con las necesidades tuteladas por un derecho social, en realidad los beneficiados por la conducta estatal no pueden gozar de este derecho como derecho subjetivo, hasta verificar si la población se encuentra en condiciones de demandar judicialmente la prestación del Estado ante un eventual incumplimiento, como explican Abramovich y Courtis ${ }^{15}$.

Los derechos sociales, salvo excepciones, no son derechos públicos subjetivos pues carecen del instrumento procesal para su tutela que exigen éstos. Según Terol, les falta la efectividad inmediata ${ }^{16}$. Éste es otro de los requisitos que necesariamente hay que valorar para abordar la cuestión de la «fundamentalidad» de los derechos, no son efectivos ni alegables por si mismos sino sólo en función de lo que disponga la legislación que los desarrolle, como determina la Constitución española en su artículo 53.3.

Por otro lado Bastida ${ }^{17}$ se refiere a la posibilidad de que los derechos sociales puedan adquirir el carácter fundamental por vía jurisprudencial aunque luego explica que ello podría entrañar una mutación constitucional tanto de las relaciones constitucionales entre el legislador y los jueces como de la posición de los derechos sociales, si constitucionalmente están concebidos como meros principios rectores con exclusión de su eficacia directa. Así advierte que aunque la posibilidad existe, salirnos del formalismo y de la rigidez de la Norma produci-

13 BASTIDA, F. (2009) «¿Son los derechos sociales derechos fundamentales? Por una concepción normativa de la fundamentalidad de los derechos», Derechos sociales y ponderación, Madrid, Fundación Coloquio Jurídico Europeo, pp. 148.

14 Ibidem, p. 139

15 Abramovich, V., y Courtis, C. (2002) Los derechos sociales como derechos exigibles, Madrid, Trotta, p. 37.

16 Terol Becerra, M. (2012) «Treinta años de desarrollo constitucional y legislativo de los derechos sociales: derechos ciudadanos y principios rectores», Derechos sociales y principios rectores. Actas del IX Congreso de la Asociación de Constitucionalistas de España, Valencia, Tirant lo Blanch, p. 56.

17 BASTIDA, ob. cit, p. 149. 
ría un el riesgo de la mutación. Ello nos conduce a pensar en más razones para comprender la importancia y la necesidad de una reforma constitucional que reconsidere la naturaleza y la ubicación (si ello sigue siendo un requisito) de los derechos sociales que deberían ser fundamentales, y que para muchos lo son aunque no formalmente.

Tras estas consideraciones previas, y siguiendo a Cascajo Castro, quien hace una precisa exposición de las dos grandes posturas doctrinales sobre este problema de la «fundamentalidad» o no de los derechos sociales, podríamos concluir que la doctrina no es unánime por supuesto, y que ambas posturas son razonables: por un lado, quienes manifiestan que no hay diferencias en cuanto su estructura y funcionamiento y por tanto nada hay que impida su configuración como derechos subjetivos y su protección jurisdiccional; y por otro, la postura formalista o nominal que entiende por derechos fundamentales sólo los calificados como tales según la Constitución ${ }^{18}$, inconveniente que se solucionaría también mediante una reforma constitucional. Independientemente de la postura adoptada, un indicador de la «fundamentalidad» de un derecho sería su vinculación con el valor de la dignidad de la persona ${ }^{19}$. En efecto, como plantea Ruiz Miguel $^{20}$, los derechos humanos conforman una categoría unitaria en lo importante, en su carácter básico, asociado a la dignidad y a la autonomía moral humana que exige reconocimiento y garantías efectivas.

Tomando la dignidad de la persona como eje en torno al cual giran los derechos, los poderes públicos asumen la responsabilidad de proporcionar a la generalidad de los ciudadanos las prestaciones y servicios públicos adecuados para subvenir sus necesidades vitales. Así el Estado social considera como tareas propias ayudar a sus ciudadanos asegurándoles su asistencia frente al paro, la enfermedad, la falta de vivienda, o la degradación del medioambiente. Estas actividades, características de un estado «asistencial», dice Pérez-Luño que son deberes jurídicos para los poderes públicos ${ }^{21}$. Son, por un lado, obligaciones para el Estado; pero por otro lado, son auténticos derechos «fundamentales» aunque no estén catalogados como tales, porque ¿se puede seguir sosteniendo que el

18 Cascajo Castro, J. L. (2012) «Derechos sociales», Derechos sociales y principios rectores, ob. cit, p. 36.

19 La dignidad de la persona, como «fundamento del orden político y la paz social» (art. 10.1 CE), obliga a reconocer a cualquier persona, independientemente de la situación en que se encuentre, aquellos derechos o contenidos de los mismos imprescindibles para garantizarla, erigiéndose así la dignidad en un mínimo invulnerable que por imperativo constitucional se impone a todos los poderes, incluido el legislador (STC 236/2007).

${ }^{20}$ Ruiz Miguel, A., ob. cit., p. 177.

${ }^{21}$ Perez-Luño, A. (1998) Los derechos fundamentales, Madrid, Tecnos, p. 193. 
derecho a la protección de la salud — por ejemplo— no es un derecho fundamental, como extensión del derecho a la vida, a la integridad física y esencial para la dignidad? Creo que no es posible mantener que no lo sea y cuando enseñamos las clases de derechos en las aulas, es habitual observar la reacción de rechazo del alumnado ante esa «categorización» de los derechos que consideran absurda. Sin embargo, el problema sigue siendo las garantías, por eso Ferrajoli ${ }^{22}$ habla de la violación de las garantías primarias positivas ante la falta de asistencia sanitaria gratuita en garantía del derecho a la salud; y entiende que ello da lugar a lagunas o a una ausencia indebida de leyes de actuación. Como explica Manuel Atienza ${ }^{23}$, ello supone que el legislador ha incumplido las obligaciones establecidas en la Constitución, lo cual nos permitiría hablar de un derecho ilegítimo. Por eso, necesitamos pensar en un cambio que dote de eficacia a los derechos sociales fundamentales que no dependa de unas leyes de desarrollo.

Es posible defender el carácter fundamental de los derechos sociales partiendo de la indivisibilidad de todos los derechos humanos. Así lo entiende también Luís Jimena, que al referirse a la atención a las personas con discapacidad (derecho que recoge el artículo $49 \mathrm{CE})^{24}$ considera que su «justiciabilidad» y su coste financiero son semejantes a los clásicos derechos fundamentales de libertad, y que tiene apariencia de fundamental por la vía del aprovechamiento conexo con otros derechos (integridad y educación o salud). El mismo análisis podría realizarse sobre otros derechos fundamentales sociales de carácter prestacional ${ }^{25}$. En ello debería centrarse también el estudio para la reforma constitucional, ya que creo — como dice Ana Rubio ${ }^{26}$ - que desarrollar los derechos sociales e incluirlos como fundamentales es uno de los mayores retos pendientes para la ciudadanía.

${ }^{22}$ Ferrajoli, L. (2011) Poderes salvajes. La crisis de la democracia constitucional, Madrid, Trotta, p. 41.

23 Atienza Rodríguez, M. (2009) «Sobre Ferrajoli y la superación del positivismo jurídico», La teoría del derecho en el paradigma constitucional, en Ferrajoli, L, Moreso, J J. y Atienza, M. Fundación Coloquio Jurídico Europeo, Madrid, p. 140.

24 Jimena Quesada, L. (2012): «El derecho a la autonomía de las personas con discapacidad», en Dir. Escobar Roca, Derechos sociales y tutela antidiscriminatoria, Pamplona, Aranzadi, p. 1408.

25 Para un estudio exhaustivo de los distintos derechos fundamentales sociales de prestación, y la tutela antidiscriminatoria en diversos colectivos y minorías, ver EsCOBAR RoCA, G. (2012) Derechos sociales y tutela antidiscriminatoria, Pamplona Aranzadi.

${ }^{26}$ Rubio Castro, A. (2013) Las innovaciones en la medición de la desigualdad, Madrid, Dykinson, p. 206. 


\subsection{Los derechos sociales ante el cambio constitucional}

Este reto evidencia la necesidad de que se realice una reforma constitucional que tenga por objeto una mejora en el ámbito de los derechos. De las dos reformas llevadas a cabo por el momento, es la última sobre el artículo $135^{27}$ la que ha suscitado una importante polémica especialmente, entre otros motivos, por lo que se refiere al retroceso en materia de derechos sociales. Son muchos los autores que se han manifestado acerca de los riesgos que para los derechos sociales conlleva. Cámara Villar ${ }^{28}$ señala que la reforma del 135 ofrece aspectos negativos desde la perspectiva de los principios que inspiran el Estado social y democrático de derecho, ya que se constitucionaliza la prioridad absoluta del pago del capital e intereses de la deuda pública frente a situaciones excepcionales que pudieran acontecer. Albertí Rovira considera que resta flexibilidad a las posibilidades de actuación económica de los poderes públicos, debilitando al Estado social; opinión también compartida por Álvarez Conde que estima que la fórmula escogida al reformar el mencionado precepto puede llegar a condicionar todas las partidas presupuestarias, alterando así los esquemas del Estado social y democrático de derecho. Existe un riesgo pues evidente de que el artículo 135

27 Sin ánimo de exhaustividad y teniendo en cuenta que el presente trabajo no se ocupa como tema principal de la reforma constitucional, sino de la construcción de un derecho concreto en el marco de una posible reforma, estos son algunos de los trabajos que se han ocupado de la reforma de 2011: En primer lugar, el número 93 de la Revista Española de Derecho Constitucional recoge las opiniones de su Consejo asesor sobre cuestiones relativas a la reforma del artículo 135, ÁLvarez CONDE et al. (2011) «La reforma del artículo 135»; y también Teoría y Realidad Constitucional, n. ${ }^{\circ} 29,1 .^{\text {er }}$ semestre 2012, dedicado monográficamente a «La reforma constitucional». Además, Blanco Valdés, R.(2011) «La reforma de 2011: de las musas al teatro», Claves de Razón Práctica, n. ${ }^{\circ}$ 216, págs. 8-18; Tajadura Tejedor, J. (2011) «Reforma constitucional e integración europea», Claves de Razón Práctica, n. ${ }^{\circ}$ 216, octubre 2011, págs. 20-29; Martín-Retortillo, M. (2012) «La reforma de la Constitución: una llamada a la responsabilidad», Revista Española de Derecho Administrativo, n. ${ }^{\circ}$ 153, enero-marzo, págs. 11-14; JIMENA QuESADA, L. (2012) «La reforma del artículo 135 de la Carta Magna española (La superación de los clichés y de la rigidez constitucional), Teoría y Realidad Constitucional, 30, pp.335-356; García-Andrade Gómez, J. (2012) «La reforma del artículo 135 de la Constitución española», Revista de Administración Pública, n. ${ }^{\circ}$ 187, enero-abril; Martínez LaGo, M. A. (2011) «Crisis fiscal, estabilidad presupuestaria y reforma de la Constitución», El cronista del Estado Social y Democrático de Derecho, n. ${ }^{\circ} 24$, diciembre 2011, págs. 10-21; Gordillo PÉrez, I. (2012) «A propósito de la reforma constitucional de 2011», El cronista del Estado Social y Democrático de Derecho, n. ${ }^{\circ}$ 25, enero 2012, págs. 31-37; y RoDRíGUEZ Bereijo, A. (2012) «La reforma constitucional del art. 135 CE y la crisis financiera del Estado», Otrosí. N. ${ }^{\circ} 11$, julio-septiembre 2012, págs. 7-16.

28 Cámara Villar, G., Albertí Rovira, E., Álvarez Conde, E. (2011) «La reforma del artículo 35», en Revista Española de Derecho Constitucional, ob.cit, p.180, 165 y 161 respectivamente. 
pueda legitimar políticas de recortes, como diría Salazar Benítez ${ }^{29}$, con las consecuencias negativas en materia de derechos.

Ante el panorama que se nos presenta se están planteando diversas propuestas sobre cómo debería estructurarse la reforma constitucional en materia de derechos y garantías. Ante un posible cambio constitucional, que podría y debería afectar a los derechos, deberíamos plantear al menos una propuesta que defina qué derechos deberían tener la máxima consideración y protección y, si es necesario incorporar algún nuevo derecho. Para ello habría que mostrar las razones que explican la necesidad de su reconocimiento ${ }^{30}$. Las razones esenciales se han puesto algunas ya de manifiesto y otras serán desarrolladas a continuación.

Entre algunas propuestas planteadas, destacaré en primer lugar aquéllas que me parecen más adecuadas desde una perspectiva de género, que es la utilizada en este trabajo, entendida — según define Ángela Figueruelo ${ }^{31}$ — como «categoría abierta, en pleno desarrollo, que favorece el ejercicio de una lectura crítica de la realidad para analizar y transformar la situación de mujeres y hombres desde relaciones no jerarquizadas ni discriminatorias». Siguiendo la planteada por la Red Feminista de Derecho Constitucional ${ }^{32}$ creo que la reforma en materia de derechos debería versar básicamente sobre dos cuestiones: por un lado, todos los derechos contenidos en la Constitución deben gozar del rango de fundamentales y les corresponden las mismas garantías; y por otro, la constitución deberá reconocer como derechos: el derecho a una vida libre de violencia de género, los derechos sexuales y reproductivos, el derecho a la conciliación de la vida personal, familiar y laboral como proyección del libre desarrollo de la personalidad, el derecho a la participación paritaria de mujeres y hombres en todos los procesos y órganos decisorios y el derecho al trabajo de mujeres y hombres en igualdad de condiciones laborales y económicas quedando prohibida cualquier tipo de discriminación por razón de género. De acuerdo con Mar Esquembre ${ }^{33}$, resulta insoslayable que el Estado Social

29 Salazar Benítez, O. (2012) «La Constitución domesticada. Algunas reflexiones críticas sobre el artículo 135», Teoría y Realidad Constitucional, num. 29, p. 423.

30 Prieto Sanchís, L. (1990) Estudio sobre derechos fundamentales, Madrid, Debate. Citando al autor: «fundamentar los derechos consiste en mostrar las razones que imponen o respaldan el deber moral de su reconocimiento jurídico», p. 18.

31 Figueruelo Burieza, A. (2012) «Introducción de la perspectiva de género en el Derecho Penal», en Figueruelo Burieza, A., Del Pozo Pérez, M. y León Alonso, M. Igualdad: Retos para el siglo XXI, Santiago, Andavira, pp. 61-62.

32 Red Feminista de Derecho Constitucional, propuesta realizada en su XII Encuentro celebrado en Biar el 16 de julio de 2015. Pendiente de publicación en «XIII Encuentro de la RFDC: Paridad y Democracia, una invitación al futuro», Ed. Conselleria de Transparència, Responsabilitat Social, Participació i Cooperaciò..

33 Esquembre Cerdá, M. (2016) «Las mujeres ante el cambio constitucional. Algunos apuntes desde una perspectiva feminista para una reforma constituyente de la Constitución espa- 
se construya no bajo la lógica productiva del mercado sino sobre la sostenibilidad de la vida, y por otro lado, que garantice una vida sin violencia; en torno a estos dos ejes debería articularse el nuevo pacto constitucional.

También otros colectivos, como las Organizaciones No Gubernamentales Amnistía Internacional, Greenpeace y Oxfam-Intermón se han manifestado ${ }^{34}$ por una revisión constitucional en materia de derechos. El documento parte de la idea de que todos los derechos se fundamentan sobre la dignidad de la persona y por tanto son igualmente importantes y deben tener un mismo régimen jurídico. Sin embargo la Constitución los clasifica, privando de «justiciabilidad»a alguno de ellos por lo que es necesario reformar esa clasificación para que todos sean eficaces. Así el manifiesto exige que no haya jerarquías entre los derechos, que ninguno prevalezca sobre otro, que todos tengan las mismas garantías y que todos puedan ser directamente invocados ante los tribunales.

En la misma línea los partidos políticos han puesto sobre la mesa propuestas concretas en materia de reforma constitucional sobre derechos y libertades. Es necesario que en un Estado social y democrático de derecho haya un entendimiento entre los distintos partidos acerca de un asunto de tal envergadura. A propósito de la reforma de 2011, Salazar Benítez ${ }^{35}$ señala que ésta es un ejemplo de que la reforma constitucional es posible si existe voluntad política. Como expresa García Fernández, si los dos grandes partidos pudieron entenderse en 2011, es un deber negociar una reforma no excluyente, sin ella no puede modernizarse la regulación de los derechos y libertades ${ }^{36}$.

Cabe destacar la propuesta del Partido Socialista de reforma constitucional en el área de derechos sociales con el fin de fortalecerlos, que se concreta en los siguientes aspectos ${ }^{37}$ :

«- Reconocer como derechos fundamentales los derechos a la protección de la salud y a la protección por la Seguridad Social ante situaciones de necesidad previstas en la Ley, incluyendo el reconocimiento del derecho a una renta o in-

ñola», Atlánticas. Revista Internacional de Estudios Feministas, núm. 1.

${ }^{34}$ Amnistía Internacional, Greenpeace y Oxfam-Intermón, «Una reforma constitucional para blindar los derechos humanos», docplayer.es/10177987-una reforma constitucional para blindar los derechos humanos.

35 Salazar Benítez, O. (2012) «La Constitución domesticada. Algunas reflexiones críticas sobre el artículo 135», ob. cit., p. 430.

36 García FernÁndez, J. (2012) «Reformas constitucionales posibles y reformas constitucionales imposibles. Notas previas a la reforma de la Constitución», Teoría y Realidad Constitucional, UNED, núm. 30, p. 313.

37 Propuesta Socialista de Reforma Constitucional por un Nuevo Pacto de Convivencia http:// www.psoe.es/propuestas/reforma-constitucional (mayo/2016). 
greso mínimo vital ante situaciones de carencia efectiva para el mantenimiento de una vida digna.

- Mejorar el reconocimiento del derecho al trabajo

- Mejorar la regulación actual sobre protección a las familias, de acuerdo con un concepto amplio de familia que comprenda las nuevas formas de convivencia, con especial atención a la conciliación de la vida familiar y laboral.

- Dotar de contenido el derecho a la vivienda y

- Reforzar los derechos medioambientales.»

En cuanto al segundo grupo de propuestas con perspectiva de género, sobre derechos y libertades, el documento se refiere a la necesidad de: «actualizar el catálogo de derechos, reordenarlo en algunas materias, incorporar concepciones sociales que se han ido abriendo paso, atender a realidades que no se pudieron tener en cuenta por el constituyente en 1978 y, en otros casos, mejorarlos atendiendo a nuestra condición de Estado miembro del Consejo de Europa y de la UE». Así, proponen:

«- Atribuir a "las personas" y no solo a los españoles el derecho a la igualdad ante la ley y a la no discriminación. Incluir nuevas causas de prohibición de la discriminación.

- Incorporar a la Constitución una regulación expresa y específica de la igualdad entre mujeres y hombres que se extienda, entre otros ámbitos, al empleo y las condiciones de trabajo, al derecho de las mujeres a su salud y a su vida, a la protección frente a la violencia de género, a la libertad de decidir sobre sí mismas, al desarrollo de una educación en valores cívicos y en igualdad, libre de sesgos de género, y a la participación política.

- Eliminar la preferencia del varón sobre la mujer en la sucesión

- Reconocer los derechos vinculados con la bioética

- Actualizar la configuración constitucional del matrimonio contemplando expresamente el derecho al matrimonio entre personas del mismo sexo.

- Mejorar la atención de los poderes públicos a las personas con discapacidad, suprimiendo la referencia a "disminuidos físicos, psíquicos o sensoriales".»

La propuesta de reforma además expresamente propone una reforma constitucional para «el reconocimiento como derechos fundamentales de derechos sociales e incorporación de garantías sobre la dotación presupuestaria de los mismos». Se pretende, además de afianzar los derechos sociales existentes dotándoles de las garantías de los derechos fundamentales, reconocer nuevos derechos y libertades. Ésta es una demanda que comparten también otros partidos. 
Por su parte Podemos ${ }^{38}$, además de demandar la derogación del artículo 135 (punto 60 del programa) incluye un extenso apartado sobre Democracia Social (del 114 al 392) poniendo en el centro la garantía constitucional de los derechos sociales, equiparando su consideración a los derechos civiles y políticos, especialmente, sanidad, vivienda y educación.

Izquierda Unida ${ }^{39}$ propone suprimir la consideración de los derechos económicos y sociales como «principios rectores de la política social y económica» ya que carecen de protección reforzada, y reconocer el derecho a unos ingresos mínimos. Su proyecto de reforma se centra especialmente en el refuerzo de la vivienda, seguridad social, protección de la dependencia y medioambiente.

Como puede observarse en materia de derechos y garantías coinciden los partidos de izquierdas, aunque también Ciudadanos ${ }^{40}$ se suma a la idea de equiparar todos los derechos, especialmente blindar los derechos sociales en sanidad, educación y vivienda, buscando así paliar el contenido del artículo 135. El documento de «Propuestas para la regeneración democrática e institucional» tiene un apartado que dispone la inclusión de una nueva sección de derechos sociales en la Constitución y su garantía presupuestaria.

Desde mi punto de vista, es preciso tener en cuenta los nuevos derechos, entre ellos algunos de los que Yolanda Gómez ${ }^{41}$ atribuía a los derechos de la cuarta generación como consecuencia de nuevas reivindicaciones ciudadanas; por ejemplo: los relativos a la protección del ecosistema, o a un nuevo estatuto jurídico de la vida humana, dentro de los que estarían los derechos reproductivos.

A ello añadiría: un derecho a la maternidad ${ }^{42}$, en conexión con los derechos reproductivos y, un derecho al cuidado, que va más allá del derecho a la salud, y que es una proyección del derecho a la vida, del derecho a una vida digna y que podría incluir no sólo el derecho a ser cuidado/a sino también el derecho a cuidar, sin que ello menoscabe otras facetas de la personalidad humana.

La ética del cuidado es un asunto recurrente en la filosofía moral feminista que tendría que observarse también de una forma más amplia en el ámbito de

38 lasonrisadeunpais.es/programa (revisado en agosto/2016).

$39 \mathrm{http} / /$ www.izquierda-unida.es/node/6266. Se refiere aquí el documento aprobado en 2005

$40 \mathrm{https} / / / \mathrm{www} . c i u d a d a n o s-c s . o r g / \mathrm{var} /$ public/sections/page-nuestras.ideas.reformas-democraticas-institucionales/reformas-democraticas-institucionales.pdf?_v $=129 \_0$ (web revisada agosto/2016).

41 Gómez Sánchez, Y. (2008): Derecho Constitucional Europeo, Madrid, Sanz y Torres, p. 65-67; y también para derechos reproductivos ver de Gómez SÁNCHEZ, Y. (1994): El derecho a la reproducción humana, Madrid, Marcial Pons.

${ }^{42}$ Marrades Puig, A. (2002): Luces y sombras del derecho a la maternidad. Análisis jurídico de su reconocimiento, Valencia, Servei de Publicacions, Universitat de València. 
la filosofía moral y del Derecho y que implica todas las demás áreas jurídicas. Desde mi punto de vista, el derecho al cuidado sería un derecho social fundamental. Social por cuanto se refiere a la prestación de atender y facilitar el bienestar de las personas, y fundamental porque es esencial para una vida digna, igual que lo sería el derecho a la salud, y por ello debe estar protegido con las máximas garantías. Éste es el principal objeto de mi estudio para este trabajo.

\section{EL CUIDADO: UNA «FUNCIÓN DE LAS MUJERES»}

Las mujeres han sido, y siguen siendo, el Estado de Bienestar del resto de la población. Esta idea de Eva Martínez ${ }^{43}$ que comparto, nos sitúa ante una realidad incontestable. El modelo de estado patriarcal se ha servido de las mujeres a través del trabajo doméstico y de las tareas de cuidado para atender a las personas dependientes, perpetuando así las funciones y los roles a ellas asignados. Son las mujeres las que asumen obligaciones, servicios y cuidados, en definitiva prestaciones sociales que deberían ser responsabilidad pública ${ }^{44}$. Las tareas de asistencia social (cuidados de niñas, niños, personas enfermas y/o ancianas) que constituyen unas necesidades mínimas de bienestar recaen en las mujeres, y ello explica, en buena parte, como argumenta Mar Esquembre ${ }^{45}$ la costosa y precaria inserción de las mujeres en el ámbito laboral, los obstáculos en la promoción profesional, la minoritaria presencia en las instituciones políticas y en puestos de responsabilidad; en definitiva, la subsistencia de la posición subordinada, en términos generales de las mujeres. Y también la ausencia de los hombres en este ámbito doméstico, pues las escasas medidas tendentes a compartir responsabilidades familiares no suelen ir dirigidas a quienes han tenido como única responsabilidad proveer económicamente al sustento de la familia.

43 Martínez Sampere, E. (2014) «Ciudadanía democrática, voluntad política y estado social», Igualdad y Democracia: el género como categoría de análisis jurídico, Valencia, Corts Valencianes, p. 446.

44 Esquembre, M. (2014) «Una Constitución de todas y todos. La reforma constitucional desde una perspectiva de género», Gaceta Sindical, reflexión y debate, nueva etapa n. ${ }^{\circ} 23$, p. 110. En este artículo Mar Esquembre analiza las propuestas de Judith Astelarra —ASTELARRA, J. (2000) en «Nuevos desafíos para el ejercicio de la ciudadanía de las mujeres», en Valcárcel, Amelia; Renau, Dolors y Romero, Rosalía, Los desafíos del feminismo ante el siglo XXI. Sevilla, Hypatia. Instituto Andaluz de la Mujer- en relación con la situación de las mujeres y las cargas familiares.

45 Esquembre, M. Ibidem, p. 111. 
En la misma línea, Laura Nuño piensa que «corren nuevos tiempos, pero no en todo. El espacio privado o doméstico sigue organizándose según las viejas reglas» ${ }^{46}$. El cambio observado entre las mujeres se ha visto acompañado por una resistencia al cambio tanto en la organización del espacio público como en la orientación de los varones al espacio doméstico. Ambos siguen instalados en las viejas reglas de la división sexual del trabajo en el espacio privado y en la invisibilidad del trabajo doméstico no remunerado, que sigue recayendo en las mujeres, quizás no exclusivamente ya, pero sí mayoritariamente.

Encarna Fernández resalta el valor ético del trabajo familiar y doméstico como actividad íntimamente ligada al cuidado y a la protección de las personas y reclama desde la igualdad de género que se reconozca el trabajo de las mujeres $^{47}$. También Octavio Salazar reclama el reconocimiento del valor social de los trabajos relacionados con el cuidado ${ }^{48}$. M. Ángeles Durán ${ }^{49}$ señala que de entre todas las tareas que se desarrollan en los hogares, las que producen mayor desazón al investigador y más debate ideológico sobre su estatuto son las de cuidar y gestar. El cuidado y las atenciones a las personas dependientes (menores, personas enfermas y/o ancianas) son el hilo conductor de una reivindicación, que comparto con tantas expertas juristas: conseguir que se reconozca como derecho y trasladar al Estado y también a los varones la responsabilidad que ha recaído tradicionalmente sobre las mujeres.

¿Por qué ha sido así siempre?, ¿hay una «ética del cuidado» específicamente femenina? Dos interrogantes que pueden tener una respuesta conjunta aunque para hallarla hay que explicar qué es la «ética del cuidado».

46 NuÑo Gómez, L. (2012) «La gestión social del cuidado: nuevos tiempos, viejas reglas», en Figueruelo Burieza, Á, Del Pozo Pérez, M. y León Alonso, M., ¿Por qué no hemos alcanzado la igualdad?, Santiago, Andavira, p. 242.

47 Fernández Ruiz-Galvez, E. (2003) Igualdad y derechos humanos, Madrid, Tecnos, pp. 167 y 168 .

48 Salazar Benítez, O. (2013) Masculinidades y ciudadanía, Madrid, Dykinson, Madrid, p. 317.

49 Durán, M. Á. (2012) «Más allá del dinero: la economía del cuidado». Discurs d'Investidura Honoris Causa per la Universitat de València, 9 de maig, de 2012, p. 50. En su magnífico discurso de investidura, M. Ángeles Durán comienza explicando cómo las experiencias personales pueden marcar nuestra existencia y nuestras investigaciones; y sitúa el inicio de sus investigaciones más importantes a partir de la reflexión a la que le llevó su experiencia de las siete lavadoras que tuvo que poner cuando nació su segundo hijo y se puso enfermo. Ella recuerda la falta de interés que este tema podía tener para sus compañeros varones y tomó la determinación de «iniciar una tranquila rebelión intelectual y decidí que la observación de la vida cotidiana tiene tanta o más importancia para la investigación en ciencias sociales que la reflexión abstracta», lo que ella llama «el estímulo de la experiencia cotidiana» p. 34 y 35. 


\subsection{La ética del cuidado}

Este concepto surge a partir de los trabajos de Carol Gilligan sobre el desarrollo de la psicología evolutiva en mujeres y hombres y según la autora ${ }^{50}$ sobre los «dos» diversos modos de hablar de problemas morales, de las dos diversas «éticas», la de la justicia y los derechos; y, la del cuidado y la responsabilidad.

Explica Carol Gilligan ${ }^{51}$ que «La moral de los derechos se basa en la igualdad y se centra en la comprensión de la imparcialidad, mientras que la ética de la responsabilidad se basa en el concepto de igualdad y el reconocimiento de las diferencias de necesidad. Mientras que la ética de los derechos es una manifestación de igual respeto, que equilibra los derechos de los otros y del yo, la ética de la responsabilidad se basa en un entendimiento que hace surgir la compasión y el cuidado».

Considerando que el feminismo critica la estructura del sistema patriarcal que se fundamenta sobre la base de la atribución de roles y de funciones específicas para los hombres y para las mujeres y la asignación de cualidades «naturalmente» femeninas, puede parecer que Carol Gilligan desde su ética diferenciada apuesta por una teoría basada en la postura tradicional (patriarcal); por ello ha sido criticada a su vez desde diversas voces feministas.

Amelia Valcárcel ${ }^{52}$, una de las autoras críticas con la tesis de Gilligan, considera que lo que Gilligan entiende por moral femenina diferente es «toda una serie de deberes inargumentados asociados además con fuertes sentimientos de responsabilidad y culpa que caracteriza a las morales previas a la libertad de conciencia..., por tanto no se está hablando de una «moral femenina» sino de la moral que es forzado a mantener todo aquél que es dependiente». Valcárcel valora negativamente el hecho de tener por naturaleza tal «conglomerado carente de sentido social e histórico», si bien yo creo que Gilligan no está afirmando que existan unos deberes o valores que «por naturaleza» pertenezcan a las mujeres sino que, si existen, son una auténtica construcción social, como confirma Ana Fascioli: «Gilligan explica que el desarrollo de la ética del cuidado en las

50 Gilligan, C. (1985) La moral y la teoría, Psicología del desarrollo femenino, Fondo de Cultura Europea, México, p. 13. Esta obra es la primera edición en español, de la edición original en inglés de 1982, In a differentvoice Psycological Theory and Women's Development, Cambridge, Harvard UniversityPress. Gilligan se basa en estudios anteriores de Kohlberg que sí ponía de manifiesto con una mirada profundamente patriarcal que la mujer nunca alcanzaría el desarrollo moral completo. Gilligan partiendo de sus estudios, aunque con otra perspectiva, desarrolla su propia teoría que entiende que habría dos éticas diferenciadas para mujeres y varones.

51 Ibidem, p. 266.

52 Valcárcel, A. (2008) Feminismo en el mundo global, Cátedra, Madrid, pp. 294 y 295. 
mujeres se debe a su tradicional rol en la esfera privada, de involucramiento con la familia y preservación de la vida. Reconoce que este rol es una construcción. La ética del cuidado es una orientación disponible para todo ser humano, pero ha estado más disponible para la mujer, por su rol de cuidadora. Así mismo, la ética de la justicia y sus valores asociados, también son un bien, sólo que ha estado en posesión del hombre» ${ }^{53}$.

Gilligan entiende que la ética del cuidado no supone dependencia o subordinación, ni tiene una connotación pasiva sino que se complementa con la justicia empoderando así a las personas en todos los ámbitos: «Mis críticos identifican el cuidado con sentimientos, a los que oponen al pensamiento, e imaginan el cuidado como un valor pasivo o confinado a alguna esfera separada. Yo describo el cuidado y la justicia como dos perspectivas morales que organizan tanto el pensamiento como los sentimientos y empoderan al sujeto a tomar diferentes tipos de acciones tanto en la vida pública como privada» ${ }^{54}$. Además considera que son complementarias: «El dominio moral se ensancha, similarmente, por la inclusión de responsabilidad y cuidado en las relaciones» ${ }^{55}$. También lo analiza de este modo Seyla Benhabib. Ella entiende que el planteamiento de Gilligan sugiere que lo deseable sería la ética de la justicia complementada por una orientación ética hacia el cuidado ${ }^{56}$.

Ana Fascioli ${ }^{57}$ afirma que definitivamente Gilligan supera la dicotomía liberal entre justicia y cuidado proponiendo una complementariedad entre ambas esferas que amplía el dominio moral y la visión de la autonomía personal, tanto de hombres como de mujeres. En ello insiste Gilligan en toda su obra: «El imperativo moral que surge repetidas veces en entrevistas con mujeres es un mandamiento de atención y cuidado, una responsabilidad de discernir y aliviar las necesidades auténticas y reconocibles de este mundo. Para los hombres, el imperativo moral parece un mandamiento de respetar los derechos de los demás y, así de proteger de toda intrusión los derechos a la vida y la autorrealización. La insistencia de las mujeres en el cuidado y la atención, al principio, es autocrítica,

53 FASCIOLI, A. (2010) «Ética del cuidado y ética de la justicia en la teoría moral de Carol Gilligan», $A C T I O$ n. ${ }^{\circ} 12$, p. 43. En su artículo Ana Fascioli resume en la nota a pie de página n. ${ }^{\circ} 6$ lo que para mí es la esencia de la argumentación contra las críticas que se le hacen a Gilligan.

54 Gilligan, C. (1993) «Replay to critics» en Larrabee, M. J. (ed) An ethic of Care, Routledge, Londres, p. 209.

55 Gilligan, C., Teoría y moral, ob. cit, p. 280.

56 Benhabib, S. (1992) «The generalized and the concrete other. The Kohlberg-Gilligan controversy and moral theory», en Situating the self. Gender, community and postmodernism in contemporary ethics, p. 180.

57 FASCIOLI, A., ob. cit, p. 55. 
más que autoprotectora, mientras que los hombres conciben inicialmente la obligación hacia los demás negativamente, en función de no intromisiones. Por consiguiente, parecería que el desarrollo para ambos sexos entraña una integración de derechos y responsabilidades mediante el descubrimiento de la complementariedad de estas concepciones distintas ${ }^{58}$.

En efecto, ante el riesgo que supone que se utilice la ética del cuidado para fines contrarios a los intereses de las mujeres —el «reduccionismo eticista» que diría Celia Amorós ${ }^{59}$ — es necesario buscar un cambio en las relaciones de poder, ésta sería la solución para «desgenerizar la ética del cuidado» ${ }^{60}$. Así lo explica Alicia Puleo en su tratado sobre el ecofeminismo, porque entiende que las críticas recibidas por la teoría de Gilligan y la ética del cuidado son similares a las recibidas por el ecofeminismo, porque ambos casos podrían estar aceptando los roles patriarcales ${ }^{61}$. En el ecofeminismo, la ética de la responsabilidad toma la forma del cuidado del medio natural ${ }^{62}$. Desde un punto de vista filosófico el ecofeminismo nos permite comprendernos mejor como especie; así como entender los motivos y las consecuencias negativas de la tajante división entre Naturaleza y Cultura. Ambos movimientos feminismo y ecologismo nos permiten desarrollar una mirada distinta sobre la realidad cotidiana, revalorizando aspectos, prácticas y sujetos que habían sido designados como diferentes e inferiores ${ }^{63}$. La procreación y la crianza han facilitado que se identificara a la mujer con algo generalmente devaluado: la Naturaleza; y así igual que la Naturaleza es sometida a la tecnología, todo lo que a aquélla se asocia (embarazo, parto, lactancia, una mayor tendencia a la expresión de los sentimientos, así como todo lo que media entre Naturaleza y Cultura como la preparación de los alimentos y la crianza de los niños y las niñas) tiene connotaciones de menor valor. Lo reproductivo versus lo productivo. De nuevo vence lo productivo. De ahí la perpetuación de las dos esferas y la crítica de un sector del feminismo, especialmente del feminismo institucional que ven arriesgadas estas posturas, tanto la ética del cuidado como el ecofeminismo. Sí, verdaderamente hay un riesgo y por ello las feministas estamos, de alguna manera, divididas entre el corazón y la razón, y de ahí que

58 Gilligan, C., Teoría y moral, ob. cit, p. 166.

59 Amorós, C. (2008) Tiempo de feminismo, Madrid, Cátedra, p. 404.

${ }^{60}$ Puleo, A. (2011) Ecofeminismo para otro mundo posible, Madrid, Cátedra, p. 61.

${ }^{61}$ Mackinnon, C. (1985) «Feminist discourse, Moral Values and the Law». A conversation», The 1984 James McCormick Mitchell Lecture, Buffalo Law Review, 34,1, p. 25 y ss.

${ }^{62}$ Puleo, ob. cit, p. 63.

63 Ibidem, p. 8. 
ahora frente las voces de las teorías del «apego» ${ }^{64}$ y la vuelta al mundo de lo «natural», se alcen las voces del feminismo institucional advirtiendo de lo peligroso que puede volverse para las mujeres una vuelta a la «Naturaleza». La solución está bastante clara pero no es fácil porque no depende sólo de nosotras y hay muchos intereses políticos y económicos en juego interesados en que todo siga como está. La solución obviamente pasa por universalizar las virtudes del cuidado que han sido históricamente femeninas y equilibrar la balanza entre lo productivo y lo reproductivo, trasladando la responsabilidad también al Estado y a los varones ${ }^{65}$.

Según, y de acuerdo con, Alicia Puleo, «en las sociedades más modernas del último siglo, las mujeres hemos incorporado masivamente ciertas características que habían sido calificadas de masculinas y son funcionales en el ámbito del trabajo asalariado, la cultura y la política. El fenómeno inverso se ha producido en un grado infinitamente menor. Si bien muchos varones comienzan a romper los moldes patriarcales, la mayoría no ha sentido suficiente atracción por las habilidades y actitudes del ámbito doméstico. Este hecho, sumado a las inercias estructurales de carácter socioeconómico nos ha conducido a la doble jornada agotadora de la superwoman». Éste es el otro gran riesgo para las mujeres si no se universaliza el cuidado: asumir nosotras las obligaciones del trabajo asalariado y de la vida pública y seguir manteniendo el protagonismo de la responsabilidad del cuidado. Por eso de nuevo todo indica que hay que extenderlo. Las conductas y habilidades de los hombres se presentan como neutras, por ello su adopción por parte de las mujeres toma la forma de conquista de aquello que se nos había negado de forma injusta. Al revés es más complicado, ellos se sienten menos atraídos por aquello que ha sido tradicionalmente devaluado. La devaluación de las actitudes y habilidades asociadas a las mujeres, vividas y concebidas como lo particular, contingente y finito frente a lo universal, necesario y eterno hacen más difícil que podamos salir de la situación de desigualdad ${ }^{66}$. Ello debe hacer-

${ }^{64} \mathrm{El}$ apego entendido como las nuevas posturas en torno al ejercicio de la maternidad desde una aproximación a la naturaleza. Todo lo relativo a la polémica en torno a la maternidad en la actualidad en la obra de BADINTER, E. (2011) La mujer y la madre, La esfera de los libros. Y también, Cristina Vega, ob. cit, p. 88.

${ }^{65}$ Son posturas que comparto con muchas autoras que he mencionado en este trabajo: la propia Alicia Puleo, Celia Amorós, Laura Nuño, Encarna Fernández; y sobre todo con Victoria Camps que en su libro «El siglo de las mujeres» hace una apasionada defensa de la ética del cuidado que debería extenderse a la sociedad en general. Por su parte Encarna Fernández propone que los actuales patrones de vida de la mujer se extiendan a todos, en Igualdad y Derechos Humanos, ob. cit, p. 171.

${ }^{66}$ En este sentido, Alicia Puleo (ob. cit., pp. 422 y 423) y, Jesús Ballesteros que trató el tema en Postmodernidad: Decadencia o resistencia y, Ecologismo personalista: «resulta urgente que los varones 
se a partir de la educación que dirija sus esfuerzos a visibilizar la importancia del valor ético de ocuparse de los demás, tanto para los jóvenes que se sienten alejados de esa realidad porque piensan que les es ajena, cuanto para las jóvenes que puedan pensar que deben desvincularse de esa idea porque ello las aleja del mundo de lo público que tanto nos ha costado a las mujeres conquistar.

«Pensar éticamente es pensar en los demás», dice Victoria Camps ${ }^{67}$, «si ese pensamiento queremos que sea una práctica, debe traducirse en medidas de justicia y actitudes de cuidado. Ambas cosas son imprescindibles. Lo único que hace la ética feminista del cuidado es llamar la atención sobre el olvido del cuidado como prescripción ética básica». Como dice Cristina Vega, «la ética del cuidado en sus distintas aproximaciones polémicas, tiene la virtud de haber puesto sobre la mesa la positividad de los cuidados y el reto que plantea su deseada universalización» ${ }^{68}$. Cuando Victoria Camps explica que sin actitudes solidarias la justicia no progresa y además, es insuficiente, está pensando en la ética del cuidado como respuesta a la virtud de la solidaridad. La ética de la justicia se dirige a las instituciones sociales y políticas y trata de establecer reglas y normas generales que valgan para todos los ciudadanos. Es una ética distante con respecto al individuo concreto: no puede tener en cuenta vínculos sentimentales y emotivos, y hasta cierto punto así debe ser, el Derecho es o debe ser general y formalista y debe huir de las emociones (al menos eso es lo que nos han enseñado a los/as juristas), pero de acuerdo con Victoria Camps, «el individuo no sólo necesita instituciones, leyes, procedimientos justos. Necesita también afecto, ayuda, compasión, compañía, cuidado. Los seres más indefensos y vulnerables no sólo reclaman del otro justicia, también reclaman cercanía, aprecio, amistad» ${ }^{69}$. Como también expresa Octavio Salazar, «el cuidado conlleva expresamente un permanente recurso a las emociones, a los afectos, a la empatía» ${ }^{70}$. Manuel Atien$\mathrm{za}^{71}$ hace referencia al sentimiento de compasión como ingrediente fundamental

asuman los hasta ahora considerados valores de mujeres, muy especialmente esta dimensión del cuidado por la naturaleza, y por todo lo que contribuye a humanizar las relaciones sociales, a hacerlas más cultas, de mejores modos...al mismo tiempo se trata de rechazar lo que se ha considerado propio de varones, en realidad infrahumano, como la guerra o la violencia». BALLESTEROS, J. (1995) Ecologismo personalista, Madrid, Tecnos, p. 104.

${ }^{67}$ Camps, V. (2003) El siglo de las mujeres, Madrid, Cátedra, p.75. La autora se considera completamente partidaria de la ética del cuidado, dedica un capítulo precioso a explicar su importancia.

${ }^{68}$ Vega Solís, C. (2009) Culturas del cuidado en transición, Barcelona, UOC.

69 Camps, V., ob. cit., p. 74.

70 Salazar, O., Masculinidades y ciudadanía, ob. cit., p. 381.

71 Atienza Rodríguez, M. (2013) Podemos hacer más Otra forma de pensar el Derecho, Pasos Perdidos, p. 106 y 107. En este capítulo el profesor Atienza hace «una lectura moral de la crisis» 
de la moral pública y de los valores de solidaridad. Dice que para la recuperación de la moral pública se precisa de sentimientos como la compasión que hace posible el discurso moral y los juicios de adscripción de responsabilidad. El pensamiento moral ilustrado y moderno es excesivamente racionalista, no concede importancia al sentimiento, y por eso, como dice Victoria Camps olvida «no sólo un aspecto importantísimo e irrenunciable de la sensibilidad humana, sino los motivos para ser moral» ${ }^{72}$.

Este sería, según Victoria Camps, uno de los dos puntos de vista compartidos por las defensoras de la ética del cuidado: que la ética de la justicia no da cuenta de los valores morales que la sociedad necesita, por eso es incompleta. El segundo se refiere a un aspecto más polémico, incluso entre las feministas, como ya se ha visto: la idea de que las mujeres están mejor preparadas que los hombres para prestar cuidado y atención.

«No se trata de propugnar esencias», dice la autora, «ni de postular una naturaleza femenina específicamente cuidadosa o cuidadora, sino de constatar la existencia de una cultura que no han hecho suya los hombres y, por lo tanto, no ha sido parte de la vida pública sino más bien considerada un estorbo para los comportamientos públicos». El problema ha sido y sigue siendo la importancia atribuida por el pensamiento liberal a los valores autoafirmativos, que son los de autonomía y los de libertad, por encima de los valores altruistas que son los propios de la esclavitud ${ }^{73}$, de aquéllas personas vulnerables o en una situación subordinada como han estado las mujeres. Volvemos a la dicotomía entre lo público y lo privado; lo productivo y lo reproductivo, lo «típicamente masculino» y «típicamente femenino». ¿Hay cualidades típicamente femeninas?: Sí y no. No hay cualidades femeninas por Naturaleza, pero sí que hay cualidades típicamente femeninas resultado de una construcción social, que si bien pudieron

y se refiere al restablecimiento de los sentimientos para que pueda existir una auténtica moral pública y solidaridad. Principalmente a los sentimientos de la compasión por el sufrimiento ajeno y la indignación por el éxito inmerecido y por el abuso de los poderosos sobre las personas más vulnerables. El espíritu de esta obra plantea una crítica al excesivo formalismo que caracteriza al Derecho, alejado de los sentimientos y principios morales, con los que las reglas tienen que conjugarse. Como también ha explicado Atienza en En «Juridificar la bioética. Una propuesta metodológica», en Bioética y nutrición (2010) eds. Alemany, M. y Bernabéu-Mestre, J. Agua Clara, Universidad de Alicante, p. 27: «El derecho es —o debe ser — una prolongación de la moral, un mecanismo para positivizar la ética», por eso no debería prescindir de los principios morales. Tambien en «Juridificar la bioética» en Isonomia, n. 8, 1998, p. 82.

72 Camps, ob. cit., p. 74.

73 Se refiere Camps aquí a la genealogía de los valores, el descubrimiento de su procedencia debería llevarnos a su rechazo: los valores altruistas como propios de la esclavitud deberían ser condenados sin miramiento...(CAMPS, ob. cit, p. 75). 
servir a la ideología liberal en el seno del sistema patriarcal para relegar a las mujeres del ámbito público, son cualidades válidas y positivas por lo que tendrían que hacerse extensibles a los hombres si se quiere construir una sociedad solidaria y justa.

Solidaridad y justicia son complementarias: allí donde la justicia no llega debe llegar el cuidado. Según estas palabras, la autora ${ }^{74}$ explica que no se trata de reivindicar el valor de lo que las mujeres siempre hicieron sino de hacer ver la falta de ese valor como ingrediente fundamental del discurso ético. Y construye un concepto de ética del cuidado sobre la base de cuatro, al menos, características fundamentales:

Primera: se constituye como un complemento a la ética de la justicia, ya que añade un enfoque particular al abstracto y general.

Segunda: se encuentra en la implicación y el compromiso directo y casi personal con los otros. El amor, el cuidado, la empatía, la compasión conectan con situaciones concretas de la persona necesitada de ayuda.

Tercera: La racionalidad debe tener en cuenta la emotividad, conectando con la idea del restablecimiento de los sentimientos morales de empatía con quienes necesitan ayuda.

Y por último: Es una ética relacional. Más que el deber lo que importa es la relación con las personas. La ley debe aplicarse teniendo en cuenta las situaciones concretas de cada persona. Victoria Camps dice que hay principios y normas pero están al servicio de las personas. Yo añadiría que el Derecho es para las personas, y si no, no tiene sentido, por eso debería fundamentarse sobre la base de esta ética.

\subsection{Los problemas del cuidado y las personas dependientes}

A pesar de nuestra preferencia por un Derecho más humano apoyado en las emociones $^{75}$, no perdemos de vista el riesgo de la subjetividad. Las emociones son subjetivas y a veces la moral es subjetiva, incluso puede derivar de prejui$\operatorname{cios}^{76}$. Los operadores jurídicos no pueden dejarse llevar por la subjetividad, está

${ }^{74}$ Ibidem, p. 76.

75 También así lo manifiesta reiteradamente Octavio Salazar en sus trabajos, otro ejemplo: SALAZAR BENÍTEZ, O. (2015) «La enseñanza del derecho constitucional como forma de acción política», Revista General de Derecho Constitucional, núm. 21. Ver en el apartado IV «reivindicando la emoción».

76 Imaginemos que la idea de la responsabilidad del cuidado estuviera sesgada por prejuicios contra determinadas personas, por ejemplo, extranjeras, de otras razas... Por eso Victoria Camps habla de «cuidar bien»: hacen falta principios para que el cuidado sea bueno» (ob. cit., p. 77). 
claro que en un Estado constitucional los jueces y juezas deben aplicar la ley, pero conjugándolas con los principios y los valores de igualdad, libertad y dignidad que fundamentan nuestras constituciones ${ }^{77}$. Yo creo que entre esos valores hay que enfatizar la importancia de los valores solidarios y entre ellos están los que han sido considerados «típicamente femeninos».

Creo que hay que insistir en la necesidad de que los valores y las responsabilidades del cuidado, tradicionalmente asignados a las mujeres, se hagan extensivos a los hombres para lograr una sociedad más justa ${ }^{78}$. A continuación habrá que ver de qué manera debe hacerse. Irremediablemente depende de la voluntad política. Una voluntad política que deben tener quienes nos representen y quienes dirijan el gobierno y la administración pública que tenga en cuenta la importancia de la educación y la transmisión de los valores solidarios y de todos aquéllos que se han considerado como propios de las mujeres y de la esfera privada. Octavio Salazar ${ }^{79}$ reclama entre ellos: la gratuidad generosa, el razonamiento práctico, la empatía, la autoridad para la mediación, la visión del detalle y la gestión circular del tiempo como imprescindibles para ser incorporados a la esfera pública y extendidos a todos. Estos son el complemento necesario para una justicia que a veces se manifiesta excesivamente abstraída de los problemas reales y cotidianos.

El problema del desempleo, por ejemplo, que debe conducir también a reorientar las políticas laborales hacia nuevos diseños. Uno de los retos de la crisis actual es justamente el cambio en la concepción del trabajo, una nueva redistribución del trabajo. Si tradicionalmente los hombres se ocupaban del trabajo fuera del ámbito doméstico y las responsabilidades domésticas y familiares eran del dominio de las mujeres exclusivamente, en la actualidad es necesario repartir las tareas del cuidado entre hombres y mujeres porque éstas siguen ocupándose principalmente de las mismas, como decíamos, las mujeres han salido de la esfera privada hacia la pública pero los hombres no han hecho el camino inverso. Por otro lado, me estoy también refiriendo a la reorientación del trabajo del cuidado remunerado, pues éste sigue siendo realizado por mujeres.

77 Atienza M., Podemos hacer más, pp. 24-26.

${ }^{78}$ Como también destaca el Overseas Development Institute Report, en su reciente informe de Marzo de 2016 «Women's work. Mothers, children and the global child crisis» (Samman Emma, Presler-Marshal, Elizabeth, Jones, Nicola), p. 74.

79 Salazar Benítez, O. (2006) «La diferencia como principio jurídico-político de una nueva ciudadanía», en Derecho Constitucional para el siglo XXI, (Ed. Pérez Royo, J., Urías Martínez, y Carrasco Durán, M.) Aranzadi, p. 729. 
El otro gran problema, y creo que el Estado (los Estados) no se ha dado cuenta de su magnitud ${ }^{80}$, ¿quién se va a ocupar de la realización de las tareas del cuidado? Hasta ahora han sido resueltas por las mujeres pero ¿qué ocurrirá cuando se terminen las generaciones de madres y abuelas cuidadoras de los menores y las personas enfermas o dependientes?

Creo que habría que poner mucha atención al análisis que María Ángeles Duran hace del problema relacionando el cuidado con la salud de las personas. En su estudio ${ }^{81}$ explica que a partir de los sesenta años, aumenta la población con enfermedades crónicas o discapacidades. En España, según datos de Naciones Unidas, los mayores de ochenta años eran el 1\% de la población en 1950, el 5\% en 2010 , y está previsto que sean el $11 \%$ en 2050 . Si estas cifras se traducen en necesidades de cuidado, los mayores de ochenta años requerían en 1950 el 2\% del tiempo destinado al cuidado de toda la población; en 2010 requerían el 10\% y en 2050 se estima que requieran el $21 \%$. Entre hoy y el año 2050 el tiempo que cada persona en edad activa tiene que dedicar al cuidado aumentará un 32\%, y habrá que detraerlo del tiempo destinado al empleo o aumentar la carga global de trabajo hasta hacerla casi insoportable si no se generan alternativas institucionales a la familia. El esfuerzo per cápita dedicado al cuidado se multiplicará por cuatro, con el agravante de que, si no cambia el modelo tradicional del cuidado, recaerá principalmente sobre una población femenina asimismo envejecida, proporcionalmente más reducida que en otros países.

En nuestro país se da una característica indiscutible, y es que la mujer aparece como proveedora casi exclusiva del «cuidado informal», siendo llamativo el envejecimiento de las mujeres, como resalta María Crespo ${ }^{82}$. Especialmente el grupo de mujeres entre cincuenta y sesenta años, que podría extenderse a grupos de mujeres más jóvenes, se encuentra en una situación bastante delicada. Por lo general mujeres de clase media que representaron el impulso emancipatorio cuando tenían entre veinte y treinta, entraron masivamente en el mercado de trabajo acogiéndose al «esquema de carrera y familia» ${ }^{83}$ y ahora se encuentran exprimidas entre el empleo y el cuidado de sus mayores. Sus opciones, a falta de servicios públicos para ello, son ocuparse personalmente o recurrir a la contrata-

${ }^{80}$ El Overseas Development Institute Report, (March, 2016) alerta sobre el problema del cuidado e incide en la necesidad de situarlo en el centro de las Agendas políticas, p. 44 y 67.

${ }^{81}$ Los datos han sido extraídos de su trabajo para el discurso de investidura como Doctora Honoris causa en 2012 por la Universitat de València: Más allá del dinero: la economía del cuidado, pp 52-55.

82 Crespo Garrido, M. (2007), «Familia y dependencia. Nuevas necesidades. Nuevas propuestas», en Lasarte Álvarez, C., La protección de las personas mayores, Madrid, Tecnos, 2007, p. 447.

83 Vega Solís, C., ob. cit., p. 30. 
ción de otras mujeres — normalmente las mujeres inmigrantes - si existen posibilidades económicas que lo permitan, aunque la gestión de lo doméstico en la familia normalmente corre de su parte.

A este cuadro debemos añadir la situación de las mujeres jóvenes que se enfrentan a la encrucijada de ocuparse o no ellas mismas del cuidado de su prole con el consiguiente riesgo que conlleva para el acceso al mercado laboral o el mantenimiento en el mismo. Lo cierto es que muchas ante la tesitura de la falta de recursos públicos, tienen que optar por ocuparse personalmente del cuidado o contratar otra persona, que siempre es otra mujer — asalariada o de la familia, por lo general la abuela- La reflexión que terminan por hacerse es que si han de contratar a alguien y el salario de esa persona prácticamente es equivalente a su sueldo acaban tomando la decisión de ocuparse ellas personalmente.

El estudio de Durán termina con la reflexión sobre quién se ocupará del cuidado de la población con enfermedades crónicas o discapacidades en el próximo futuro. La autora muestra su preocupación por el papel que desempeñará el cuidado en el contrato social que vincula entre sí a todos los ciudadanos y a los ciudadanos con el Estado y las instituciones sociales. Y sugiere un cambio de orientación en la economía y la política que considere el trabajo de cuidado como una actividad productiva, y una nueva sociología que coadyuve a implantar un modelo más justo en el reparto de la carga total del trabajo. También cabe añadir la atención específica a la Tercera edad ante la evolución reciente de nuestra sociedad, como pone de manifiesto Carlos $\mathrm{Vidal}^{84}$, que genera en los poderes públicos la obligación de incrementar la atención prestacional asumiendo nuevas políticas sociales.

Nosotros no somos demasiado diferentes del resto de países en Europa en cuanto a la solidaridad familiar, si por ella se entiende una forma de actuar responsable frente situaciones de necesidad ${ }^{85}$; sin embargo, nos diferenciamos los países mediterráneos de los nórdicos, anglosajones o centroeuropeos en que recurrimos al cuidado informal de forma generalizada como estrategia privada

84 Vidal PRAdO, C. (2007) «La protección constitucional de la Tercera Edad», en Lasarte Álvarez, C. La protección de las personas mayores, ob. cit., p. 20.

85 La Ley 39/2006, de 14 de diciembre, de Promoción de la Autonomía Personal y Atención a las personas en situación de dependencia, describe los cuidados profesionales, los cuidados no profesionales y la figura del asistente personal como las distintas posibilidades de atender a las personas dependientes. Esta Ley ha supuesto una avance importante en el desarrollo de la atención a las personas en especial situación de vulnerabilidad, el problema sigue siendo la falta de recursos materiales para hacerla efectiva. Sin embargo debido a que su implantación ha sido progresiva (acabó de implantarse definitivamente en julio de 2015 al incorporarse los dependientes de Grado I (moderados) habrá que ir evaluando su nivel de eficacia. 
de las familias para la prestación de $\operatorname{cuidados}^{86}$. Y esto supuestamente se explica por razones estructurales como el escaso desarrollo de servicios públicos o la reducida participación laboral femenina, pero también por el diferente concepto de familia que caracteriza los países latinos. Todo ello hace que seamos más conscientes de la necesidad de fundamentar un derecho al cuidado.

\section{COMO CONCLUSIÓN: UN DERECHO AL CUIDADO}

El previsible aumento de personas necesitadas de cuidados, la escasez de servicios públicos para su asistencia, el tipo de cuidado informal prestado casi exclusivamente por mujeres que tienen que afrontar problemas y dilemas personales que afectan al libre desarrollo de la personalidad y también al derecho a la igualdad, pero sobre todo, la inexistencia de una ética de la solidaridad y de la responsabilidad extendida socialmente conducen a pensar en la conveniencia de un derecho al cuidado. El Estado tiene que asumir que las generaciones de madres y abuelas que tradicionalmente se han ocupado del cuidado de menores, personas enfermas, ancianas o dependientes se acaba, las mujeres no están dispuestas a seguir prestando esa función en exclusiva: ni ser cuidadoras exclusivamente ni ser exclusivamente ellas las que cuidan. Comparto la idea de Javier De Lucas $^{87}$ cuando dice que «el Estado no puede ser neutral, no puede dejar de comprometerse con el significado de los bienes sociales elementales, el Estado no puede abandonar el principio de solidaridad sino que debe considerarlo como un imperativo». El principio de solidaridad debe extenderse a todos y debe ser asumido por el Estado: Esto puede hacerse desde diversas perspectivas: las políticas públicas ${ }^{88}$ deben reorientarse a la solidaridad y a la asistencia de las personas más vulnerables; el legislador debe regular estos valores y los jueces deben tomarlos en consideración al dictar sus resoluciones, ya que como explica Atienza, los jueces tienen que sentirse vinculados no sólo por el tenor de las normas, sino también por las razones subyacentes a las mismas ${ }^{89}$.

86 García Sainz, C., Santos Pérez, M. L., Valencia Olivero, N. (2011) Inmigrantes en el servicio doméstico, Talasa Ediciones, p. 30.

87 De Lucas, J. (2003) Blade Runner. El Derecho, guardián de la diferencia, Valencia, Tirant lo Blanch, p. 63.

${ }^{88}$ La principal conclusión/reivindicación del Informe del ODI (Overseas Development Institute) (marzo, 2016) es «la necesidad de reconocer el cuidado como un asunto central de las políticas públicas», p. 44 y 67.

89 Atienza Rodríguez, M. (2011), «Dos versiones del constitucionalismo», Doxa, Cuadernos de Filosofía del Derecho, n. ${ }^{\circ} 34$, p. 83. 
En el ámbito constitucional, estamos hablando de la fundamentación de un nuevo derecho para un posible cambio constitucional. Fundamentar los derechos consiste en mostrar las razones que imponen o respaldan el deber moral de su reconocimiento jurídico ${ }^{90} \mathrm{y}$ creo que todas las anteriormente mencionadas constituyen una buena defensa para su reconocimiento. Por tanto, la necesidad existe y requiere de la intervención del Derecho, porque como ya hemos dicho, el Derecho es para las personas. Citando a De Lucas y Añón «el recurso a las necesidades supondría aceptar que en ellas se encuentra el sustrato antropológico de los derechos, de forma que reconocer, ejercer y proteger un derecho básico significa, en última instancia, que se pretende satisfacer una serie de necesidades, entendidas como exigencias de una vida digna» ${ }^{91}$, volvemos a la cuestión de la dignidad que sería en definitiva la razón última de un derecho al cuidado.

Como dice Asunción Ventura, las mujeres han posibilitado con su trabajo en el ámbito privado, las condiciones de subsistencia necesarias para la existencia de la dignidad; sin embargo, esta actividad desarrollada en aras de la dignidad las ha situado a ellas mismas en una posición de desventaja ${ }^{92}$. Coincido con Eva Martínez en que no hay democracia sin igual dignidad humana e igualdad de derechos de todas las personas, por ejemplo, sin el universal de la igualdad de mujeres y hombres. Ni sin la reducción de desigualdades sociales hasta el punto de hacer posible una digna calidad de vida para toda la población ${ }^{93}$.»La igualdad necesita cambios: una nueva jurisprudencia, una nueva relación entre la vida y la ley», como ya anunciaba Mackinnon ${ }^{94}$.

Los llamados «nuevos derechos sociales» ${ }^{95}$, es decir los derechos del cuidado a las personas y que por tanto constituyen necesidades humanas básicas para una vida digna, se formulan en un contexto de cambio que exige una intervención urgente del Derecho para reconocerlos y aplicarlos. Habría que estudiar detenidamente cómo deberían ser formulados pero en principio cabría considerar que un derecho al cuidado no se agotaría en su vertiente «pasiva» a ser cuidado, sino también en un derecho a cuidar, lo que implicaría por ejemplo suspender la

90 Prieto SAnChís, L. (1990) Estudio sobre derechos fundamentales, p. 18, citado en la nota n. 30.

${ }_{91}$ De Lucas J. y AÑón, M. J. (1990) «Necesidades, razones, derechos», Doxa, 7, p. 75.

92 Ventura Franch, A. (1999) Las mujeres en la Constitución española de 1978, Madrid, Ministerio de Asuntos Sociales, Instituto de la Mujer, p. 210.

${ }^{93}$ Martínez Sampere, E., ob. cit, p. 447.

94 Mackinnon, C. (1995) Hacia una teoría feminista del Estado, Madrid, Cátedra, p.445.

95 Tobío, C., Agulló Tomás, M. S., Gómez, V. y Martín Palomo, M. T. (2010) El cuidado de las personas: un reto para el siglo XXI, Colección Estudios Sociales, Fundación «La Caixa», pp. 182 y 183. Las autoras hablan incluso del derecho a no cuidar como otra posible vertiente del derecho, como un nuevo argumento del debate, pero no coincido con ello porque sale fuera del ámbito de la solidaridad extendida que entiendo, debería fundamentar el derecho. 
actividad laboral o disfrutar de unas condiciones especiales temporalmente en tanto que la necesidad perdure, lo que permitiría una implicación más igualitaria de los hombres en el cuidado. Lógicamente para lograr los objetivos propuestos - la formulación del derecho en sus dos vertientes y todo lo que ello conlle$\mathrm{va}^{96}$ - se necesita voluntad política. Como expone Ferrajoli, cuando se objeta que el principal problema para hacer efectivos los derechos sociales es el económico - los derechos sociales cuestan-, no se tiene en cuenta que resulta mucho más costosa su falta de satisfacción, ya que si todos los derechos de libertad constituyen factores de progreso, en la misma medida lo son los derechos sociales porque son esenciales para la seguridad y tienen efectos positivos en la economía. «Los problemas no son teóricos ni técnicos, sólo políticos: «ligados a la falta de disposición de los poderes más fuertes de someterse al Derecho y a los derechos ${ }^{97}$.

El Derecho se ha ocupado de los grandes temas que afectan a cuestiones vitales a través de la bioética ${ }^{98}$. Pero si la bioética es, en definitiva, la ética de la vida, éste asunto no puede serle ajeno. No sólo concierne a la dignidad de la vida las decisiones sobre cuestiones trascendentales en relación a su inicio y a su final; y no sólo estas cuestiones deben ser importantes para el Derecho, sino también aquellas situaciones o periodos de especial vulnerabilidad o dependencia que pueden acaecer en cualquier momento de la vida. Éste sería otro reclamo más para la intervención del Derecho. Como dice Atienza en el título de su libro ${ }^{99}$, «Podemos hacer más», podemos pensar el Derecho de otra forma para que sea más humano; podemos acercar el derecho a la vida, como diría también MacKinnon ${ }^{100}$. Recogiendo unas palabras de Ferrajoli ${ }^{101}$, debemos creer que la tutela de la vida es el objeto del Derecho y la razón de las instituciones políticas, entonces las condiciones para una vida digna deben entrar en el pacto de convivencia. Por eso creo que el pacto de convivencia debería ser reformulado para un futuro

96 Me refiero a las reformas legislativas correspondientes y a la labor que deben desempeñar los jueces que deben mirar con otra perspectiva.

97 Ferrajoli, L. (2013) «Derechos sociales y esfera pública mundial», Los derechos sociales en el estado constitucional (Coord. Espinoza de los Monteros, J. y Ordóñez J.) Valencia, Tirant lo blanch, p. 53-56. y p. 59 la cita literal.

98 Cuestiones relativas al consentimiento en tratamientos médicos, a la autonomía para decidir si queremos seguir con vida en condiciones que no consideremos dignas, técnicas de reproducción asistida, trasplante de órganos y ahora últimamente la maternidad subrogada que es uno de los «problemas difíciles» por poner ejemplos que podrían extenderse mucho más.

99 Atienza, M., Podemos hacer más, ob. cit.

100 Mackinnon, C. Hacia una teoría feminista del Estado, ob. cit. p. 445.

101 Ferrajoli, L. «Derechos sociales y esfera pública mundial», ob. cit., p. 52. 
cambio constitucional que tuviera en cuenta las nuevas expectativas para una vida mejor en igualdad de condiciones.

La sociedad democrática avanzada, a la que se refiere el Preámbulo de nuestra Constitución, lejos de ser un concepto estático, constituye una realidad dinámica, como sugiere Torres del Moral, que mira hacia el futuro «en pos de nuevas cotas de libertad, de justicia y de progreso» ${ }^{102}$, y para la consecución de estos fines es necesario a veces ser conscientes de la necesidad de crear nuevas categorías jurídicas que se adapten a las nuevas condiciones sociales. El Derecho, y más aún el Derecho Constitucional, podría ser más activo, crítico, incluso combativo como sostiene Carlos de $\mathrm{Cabo}^{103}$, para lograr un orden económico y social justo. Remedio Sánchez ${ }^{104}$ habla de la función transformadora del derecho constitucional como transformación social que se deriva de los contenidos sociales y del artículo 9.2 de la Constitución española. La participación plena de la ciudadanía y el valor asignado al concepto de vida digna exigen revisar aquellos conceptos que no se incluyeron en 1978 y que deberían considerarse para elaborar el nuevo pacto constitucional. Creo, en línea con la tesis de Ana Rubio ${ }^{105}$, que hay que asumir el reto de la creación de nuevos conceptos, teorías y categorías jurídico-políticas que sirvan para argumentar el cambio constitucional, apostando por el reconocimiento del cuidado no sólo como un nuevo derecho sino también como fundamento del nuevo pacto social.

Title:

The new social rights: the right to care as the foundation of the constitutional pact.

\section{Summary:}

1. Evolution and concept of social rights: the new historical and social context. 1.1 The evolution of social rights. 1.2 The fundamental nature of social rights. 1.3 The social rights in the face of the cons-

102 Torres Del Moral, A., «Democracia militante», ob cit, p. 222.

103 De Cabo Martín C. (2013) «Propuesta para un constitucionalismo crítico», Revista de Derecho Constitucional Europeo, n. ${ }^{\circ} 19$, p. 393-394.

104 Sánchez Ferriz, R. (2009), El Estado Constitucional, Valencia, Tirant lo Blanch, p. 34.

105 Rubio Castro, A. (2013), Las innovaciones en la medición de la desigualdad, Madrid, Dykinson, p. 235. 
titutional change. 2. The care: a «role of women». 2.1 The ethics of care. 2.2 The problems of care and dependent persons. 3. Conclusion: A right to care.

\section{Resumen:}

Nos encontramos ante un momento histórico y político que sugiere una revisión constitucional, con necesidades específicas y diferentes a las de 1978. Existen nuevas demandas que exigen que se revise el pacto constitucional. Algunas afectan directamente al catálogo de derechos, especialmente a los llamados derechos sociales, y se refieren por un lado, a la necesidad de otorgar a los derechos sociales ya reconocidos la consideración de fundamentales con todo lo que ello conlleva; y por otro, a la necesidad de crear nuevos derechos.

El previsible aumento de personas necesitadas de cuidados, la escasez de servicios públicos para su asistencia, el tipo de cuidado informal prestado casi exclusivamente por mujeres que tienen que afrontar problemas y dilemas personales que afectan al libre desarrollo de la personalidad y también al derecho a la igualdad, pero sobre todo, la falta de una ética de la solidaridad y de la responsabilidad extendida socialmente exigen el reconocimiento de un derecho al cuidado.

Por ello, entendemos que este análisis debe ser realizado desde la perspectiva de género, entendida como una categoría de análisis abierta que apuesta por el ejercicio de una lectura crítica de la realidad para transformar la situación de mujeres y hombres en la sociedad en aras de la igualdad real que postula nuestra Constitución y partiendo de la función transformadora del Derecho Constitucional.

La ética del cuidado, como una forma de aproximarse a los problemas morales «típicamente femenina», ha servido para señalar la importancia del cuidado como prescripción ética básica; y por tanto esta ética debería guiar la nueva configuración del catálogo de derechos para una futura revisión de la Constitución.

Los derechos del cuidado a las personas y que por tanto constituyen necesidades humanas básicas para una vida digna, se formulan en un contexto de cambio que exige una intervención urgente del Derecho para reconocerlos y aplicarlos. La configuración de un derecho al cuidado podría tener una doble vertiente: la de ser cuidado, obviamente, pero también la de cuidar, lo que implicaría por ejemplo suspender la actividad laboral o disfrutar de unas condiciones especiales temporalmente en tanto que la necesidad perdure, lo que permitiría una implicación más igualitaria de los hombres en el cuidado.

El cuidado ha sido tradicionalmente una función de las mujeres, ellas se han ocupado del cuidado de menores, enfermos y personas depen- 
dientes; sin embargo esta función tan encomiable y necesaria para facilitar las condiciones de una vida digna, las ha colocado en una situación de desventaja dificultándoles su participación en la esfera pública. La solución posible es la asunción por parte de toda la sociedad de que la esfera privada y en definitiva, las tareas de cuidado han de ser compartidas entre hombres y mujeres; y lo más importante: que esa reflexión debe pasar a las agendas políticas influyendo en la legislación y en las políticas públicas.

\section{Abstract:}

We are faced with a historical and political moment which suggests a constitutional revision, with specific and different needs from the 1978 needs. There are new needs that require to review the constitutional pact, some directly affect the catalogue of rights, especially to the so-called social rights, involving on the one hand, the need to grant social rights already recognized the consideration of basic with everything that that entails; and secondly, the need to create new rights.

The foreseeable increase of people in need of care, the shortage of utilities for their assistance, the kind of informal care provided almost exclusively by women who are faced with problems and personal dilemmas that affect the free development of the personality and the right to equality, but above all, the lack of an ethic of solidarity and the responsibility socially extended require recognition of a right to care.

Therefore, we understand that this analysis should be done from the perspective of gender, as a category of analysis open committed to the exercise of a critical reading of reality to transform the situation of women and men in society for the sake of real equality postulated in our Constitution and on the basis of the transformative role of the constitutional law.

The ethics of care, as a way of approaching the moral problems «typically feminine», has served to emphasize the importance of care as basic ethical prescription; and therefore this ethics should guide the new configuration of the catalogue of rights for a future revision of the Constitution.

The rights of care and which therefore constitute basic human needs to a dignified life, formulated in a context of change, require urgent intervention of the law to recognize them and apply them. The configuration of a right to care could have a twofold purpose: not only the right to be cared for, but also, the right to care for, implying for example to suspend work or enjoy special conditions temporarily 
while the need persists, which would allow a more equal involvement of men in care.

Care has traditionally been a function of women, they have dealt with the care of children, sick and dependent persons; however this function so commendable and necessary to facilitate the conditions for a dignified life, has placed them at a disadvantage, making it difficult for them their participation in the public sphere. The possible solution is the assumption by the whole society that the sphere private and ultimately care tasks have to be shared between men and women; and most importantly: this reflection must have a political influence in legislation and public policies.

\section{Palabras Clave:}

Derechos sociales, Cambio constitucional, Ética del cuidado, Derecho al cuidado.

Key words:

Social rights, Constitutional revision, Ethics of care, Right to care. 